\title{
The impact of different approaches to the teaching of Grade 5 fraction by three experienced teachers
}

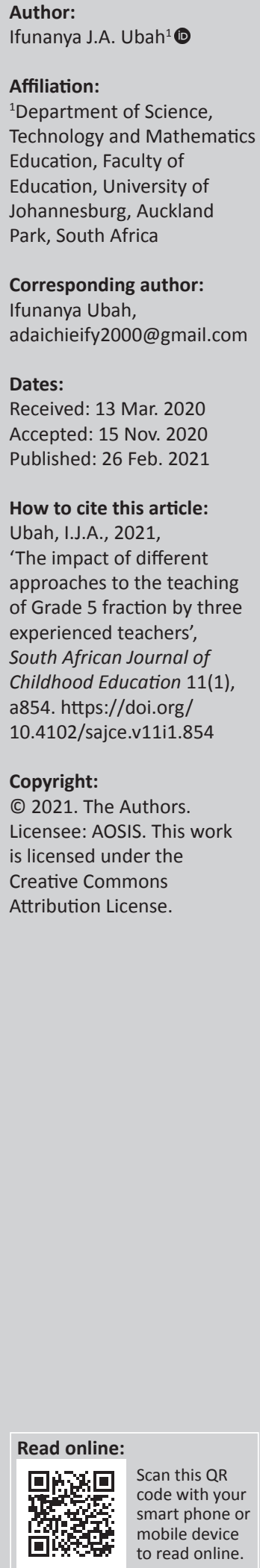

Background: Many teachers for different reasons recognise the teaching of fraction as a challenge. This research explored the teaching of fraction in Grade 5 by three experienced teachers (Ben, Greg and Will) in KwaZulu-Natal province, South Africa.

Aim: The purpose of this study was to investigate the impact of different approaches to the teaching of Grade 5 fraction by three experienced teachers.

Method: Three teachers and 177 learners were purposively sampled for this study. Classroom observations, interview and fraction achievement test (FAT) were instruments used for data collection. Hence, this study employed a mixed method, where both quantitative and qualitative data sets were collected at the same time, and the data were analysed at the same time in order to discuss the findings.

Results: The quantitative data were analysed using descriptive statistics and analysis of covariance (ANCOVA), whilst the qualitative data were analysed in themes. The results showed that learners of teacher Ben performed significantly better than those of teachers Will and Greg. The findings revealed that a combination of good practices and appropriate use of multiple representations by teacher Ben improved his learners' achievement in addition of fraction more than other learners taught by the other two teachers.

Conclusion: The study recommends that mathematics teachers should endeavour to facilitate learners' conceptual knowledge of fraction by using appropriate teaching approach in their instruction, namely, learner-centred approach, activity-based learning, use of mother tongue for clarity and use of multiple representations. This recommendation will improve learners' knowledge and conceptual understanding of fraction and algebra in its entity.

Keywords: addition of fraction; analysis of covariance; descriptive statistics; teaching approach; use of representations.

\section{Introduction}

Fraction often represents the first hurdle experienced by primary school learners when learning mathematics because it is one of their first experiences with a math concept beyond the basic skills of addition, subtraction, multiplication and division (Chinnappan 2006). It is important that learners feel comfortable and confident in their understanding of fraction because the concept forms a building block for other mathematical skills, such as algebra. Researchers argue that children generally perform badly in algebra questions involving fraction and that knowledge of fraction is crucial for success in algebra (Booth, Newton \& Twiss-Garrity 2014). Norton and Boyce (2013) and Siegler, Thompson and Schneider (2011) argued that fraction is very difficult to teach, most cognitively challenging and most essential for advanced mathematics.

The rationale for this study emerged from the personal experiences of the author who observed during her teaching practice supervision that many primary school pre-service teachers teach fraction in terms of rules and isolated procedures. The author was concerned that the preservice teachers' teaching approach did not emphasise making connections between multiple representations, and they did not use appropriate diagrams whilst trying to teach learners about how to solve a given problem on fraction; they instead paid attention to the final solution in symbolic form. The author was curious about whether experienced teachers teach fraction in a similar manner or whether they were able to devise teaching approaches that enable learners to gain a thorough conceptual understanding of fraction. Hence, in this study, the author set out to explore the impact of different approaches in the teaching of Grade 5 fraction by three experienced teachers. 


\section{Research questions}

The research questions explored in this study were:

- How did the Grade 5 experienced mathematics teachers' teach addition of fraction?

- Was there any difference in the learners' mean achievement scores on tasks based on addition of fraction?

\section{Literature review}

According to Chinnappan and Forrester (2014), fraction requires a great deal of attention because it presents a hurdle as learners attempt to transfer their understanding of whole numbers to a new but related class of numbers. A key construct that underpins the learning of fraction is the part-whole relationship. Kieren (1976) was the first to propose that the notion of part-whole relationship should be considered as the focus for developing understanding of the four subordinate constructs of fraction: ratio, operator, quotient and measure. The ratio sub-construct promotes the concept of equivalence and the process of solving for equivalent fraction. The sub-construct quotient promotes the understanding of subtraction and division of fraction. The sub-constructs operator and measure are useful for the development of the understanding of multiplication and addition of fraction, respectively. Lastly, understanding of ratio, operator, quotient, measure and part-whole relationship of fraction is considered a prerequisite for solving problems on equivalence, addition, subtraction, multiplication and division of fraction.

Fuchs et al. (2013) argued that the part-whole and the measurement conceptual interpretation of fraction are important milestones in the early developmental knowledge of fraction. The part-whole relationship can also be expressed as the relationship between a subset of a group of objects and the group itself. In this part-whole interpretation, the fraction is seen as a set which is subdivided into equal-sized parts (Fuchs et al. 2013). Charalambous and Pitta-Pantazo (2005) recommended that the relationship between the part-whole interpretation and the additive operations of fraction should be emphasised during instruction, in order to promote the process of learning addition of fraction. Furthermore, Charalambous and Pitta-Pantazo (2005) observed that the part-whole interpretation of fraction should be considered as essential for developing learners' understanding of fraction. Barton (2008) suggested that the teaching of the different operations of fraction should be directly linked to specific interpretation of fraction.

The measurement interpretation of fraction, which is often neglected, is an important one because of its links to cardinal size (Hecht, Close \& Santisi 2003). A strong understanding of a fraction as a measure, such as a length on a number line, is crucial also for learners' future mathematics achievement (Boyce \& Norton 2016; Siegler et al. 2011). The measurement interpretation may help learners to develop a stronger understanding of the magnitude of fraction, an area which is identified as a weak link in the development of fraction schema of many learners (Siegler et al. 2011; Ubah \& Bansilal 2018). Although the measurement interpretation is not as instinctive as the part-whole understanding, it can help learners make sense of number properties, such as the density of rational numbers and connections between representations (National Council of Teachers of Mathematics 2014; Siegler et al. 2011).

Recent research has pointed to the importance of drawing upon and making connections between representations when teaching fraction (Cramer, Post \& delMass 2002; Cramer \& Wyberg 2009; NCTM 2000, 2014). The NCTM (2014) defines mathematical connections in Principles and Standards for School Mathematics as the mathematical ideas that interconnect and build on one another to produce a coherent whole. Representations enable learners to make connections between their own experience and mathematical concepts and, therefore, gain insight into these abstract mathematical ideas (An, Kulm \& Wu 2004; Duval 2006; Flevares \& Perry 2001). In recognising the benefits of using visual representations, the possible difficulties involved in using these in the classroom must also be acknowledged. For instance, the circle model can be problematic for learners when representing a fraction with an odd denominator, such as two-third (Wu 2014).

According to Odili (2006), some teachers teach only rules and procedures for manipulating mathematical idea, and sometimes when visual aids such as concrete representations are used, they are used wrongly. Muraka's study (2008) observed that the consistent and coherent use of one type of representation can bridge student understanding over time because of its focus on mathematical relationships and problem-solving processes. Many researchers argue that the use of representations can be more effective and when concrete and semi-concrete aids are used in teaching and learning of mathematics, the conceptual understanding is improved (Azuka 2009; Barmby et al. 2014; Naidoo 2011). Representations commonly used in the early years of schooling include concrete materials, diagrams or pictures, symbols, spoken language and experiences and are used to present mathematical idea with the aim of making it accessible to learners (Green \& Hall 1997). If particular representations are to be used in the classroom, then teachers need to support learners in learning to interpret representations (Flevares \& Perry 2001), through providing effective experiences to support learners' progression onto using these different representation.

The NCTM (2014) advises that effective teaching of mathematics engages learners in making connections amongst mathematical representations to deepen understanding of mathematical concepts. Tripathi, Mehrotra and Dutta (2008:439) emphasised that connections between and within representations are like examining the concept through a variety of lenses, with each lens providing a different perspective that makes the concept richer and deeper. During classroom instructions, teachers are constantly interacting, giving instructions and directing the 
learners through speech. Vygosky (1978) cited in Vanderburg (2006) posited that language is the heart of all instructions whether oral or written language. It is necessary for teachers to use a language that every learner understands because if language of instruction is not learner-friendly, then communication becomes a problem.

Interestingly, some learners feel that it is easier to understand mathematics when taught through their home language (Van Laren \& Goba 2013). Essien (2018) observed that various mathematics education researches on the role of language point to the intricate link between language competence and mathematics performance. Learners whose first language is the same as the language of instruction are familiar with the linguistic structure they encounter in mathematics instructions (Barwell 2009). In some instances, learning mathematics through one's home language can be perceived negatively by the society, resulting in derogatory names being given to the group taught in their home language and poor general performance (Odili 2006). Research has shown that South African schools preferred English and not learners' home language as a language of instruction in mathematics classroom (Setati 2008).

However, Van Laren and Goba (2013) suggested that whilst teaching mathematics to second language learners, teachers should introduce two languages simultaneously for clarity of the mathematical terms and concepts. Setati, Chitera and Essien's (2009) systematic review revealed that research on the role of language in primary school level was insignificant compared with the role of language in mathematics at other levels of education. Language challenge reduces the learners' confidence level to speak up in the classroom and as a result their doubts do not get clarified, which affects their academic performance. In view of these, the challenges that learners experienced in developing deep understanding of fraction are either because of the nature of fraction or the instructional approaches employed to teach fraction (Barton 2008; Behr et al. 1993).

\section{Theoretical framework}

\section{The constructivist theory}

Bruner is one of the founding fathers of constructivist theory (Nnachi 2009). The constructivist theory is basically a theory based on observation and scientific study about how people learn (Nnachi 2009). The central idea of constructivism is that human learning is constructed in such a way that learners build new knowledge upon the foundation of previous learning. Various teaching approaches were derived from constructivist theory, which suggests that learning is accomplished best by using a hands-on approach. Constructivist theory is based on the fundamental assumption that a learner actively seeks new information and is actively engaged in the process in the way he or she gains, assimilates and utilises knowledge. According to Stoblein (2009), vital constructivist learning principles include the following: (1) learning is an active process: a student needs an input of 'doing', and is engaged with the world, from which the learner constructs a meaning and systems of meaning. (2) Learning is engaging: teachers need to provide activities that engage the mind and the hands. (3) Learning occurs contextually: learning experiences are interwoven with life experiences. (4) Learning builds on previous knowledge: teachers' efforts must be connected to the state of the learner and provide a path into the subject based on his or her previous experience. (5) Learning takes time: students need to revisit ideas, ponder them, try them out, play with them and use them. (6) Learning is a social activity: learning experiences are connected with each other's minds (e.g. teachers and peers).

Social constructivism strongly influenced by Vygosky's (1978) work suggested that knowledge is first constructed in a social context and is then taken up by individuals (Eggen \& Kauchak 2004). Vygotsky asserted that in social constructivism interactions, teachers help the learner to get to his or her own understanding of the content learning in an active manner. According to Zaretskii (2009), the teacher is the mediator in the learning process and is responsible for creating a conducive classroom environment to ensure that all learners are active participants in the learning process. In addition, Klob (1984) argued that concrete experience should be included as part of the learning process and requires learners to test their knowledge by acting upon the environment, thereby giving reliable and trustworthy knowledge. This study explored the impact of different approaches to the teaching of Grade 5 fraction by three experienced teachers.

\section{Methodology Research design}

This study used a mixed-methods approach (Creswell 2011), where both qualitative and quantitative data sets were collected at the same time, and the data were analysed at the same time in order to discuss the findings. Qualitative research methods permit an in-depth investigation of single or small number of units at a point (over a period) in time (Hsieh \& Shannon 2005). A qualitative research method, through interview and observational tools, was used to observe the approaches used by three experienced teachers (each from a different school) in teaching addition of fraction in three schools and to investigate whether any of the teaching approaches was more successful than the others. However, the quantitative component of the study used a quasiexperimental design, which specifically uses nonequivalent control group designs in which pre-test and post-tests were carried out. The author adopted a quasi-experimental design because it was not logistically feasible or ethical to conduct a randomised controlled trial; rather, intact classes were used. According to Harris et al. (2006), this design will demonstrate causality between the treatment and the outcome. 


\section{Selecting participants}

Three primary school teachers, with their learners totalling 177 Grade 5 learners, took part in this study. Purposive sampling was used to select teacher participants who were experienced mathematics teachers well informed about the topic of interest. The purpose of using purposive sampling is to select information-rich cases whose study will illuminate the questions under study (Ratcliff 2012).

\section{Data collection}

Qualitative data to describe the teaching approaches used by three experienced teachers in teaching addition of fraction to Grade 5 learners were obtained by conducting individual semi-structured interviews and lesson observation. Each teacher presented two lessons on addition of fraction, which the author validated to check their suitability for the study. The author spent two successive days (day 1 and day 2) in each school, watching two lessons on addition of fraction. The interviews were conducted on the second day after the second lesson and were conducted during break for $40 \mathrm{~min}$. The semi-structured interview questions were used to gain a clearer understanding of these teachers' teaching approaches in teaching addition of fraction and of their profile and experiences.

The quantitative data obtained from achievement test items (see Appendix 1) of primary school learners measured using fraction achievement test (FAT), was developed by the author. The FAT consists of 40 items based on addition of fraction drawn from the Curriculum Assessment and Policy Statements (CAPS) for intermediate phase school learners (DoE 2012). The pre-FAT was administered to the learners before the actual classroom instruction and the post-FAT test items were administered to the same learners after the treatment. The author assumed that the test items must have undergone validity and reliability test but for confirmation, the test items were validated by two postdoctoral research fellows that checked the relevance, suitability and clarity of the test items for the study.

\section{Data analysis}

Analysis of data entails breaking down the information gathered into elements to obtain responses to research questions (Sauro 2015). In this study, the qualitative data from semi-structured interviews and classroom observations were analysed using thematic analysis. The interview data were organised to get an overview of what it revealed, and classroom observations were grouped into manageable themes (Ratcliff 2012). The learners' written responses FAT were analysed using descriptive and inferential statistics (analysis of covariance [ANCOVA]).

\section{Ethical consideration}

Approval to conduct the study was obtained from the teachers who happen to be my students before lesson observation and interview. Learners and their parents were asked to give consent to having their scripts analysed. To protect the identities of the teachers, pseudonyms 'Ben', 'Will' and 'Greg' were used.

\section{Research findings}

This section is organised according to the two research questions, which cover the qualitative and quantitative aspects of the study.

Research Question 1: How did the Grade 5 mathematics teachers teach addition of fraction?

To address this research question, we first presented a brief description of the three teachers' cases. The analysis began by acquiring a rich profile of each of the three participants and description of their teaching approach. They were followed by a detailed transcript of semi-structured interviews and classroom observations focused on the individual teachers' teaching approach and how they used them.

\section{Teacher 1: Ben}

Ben was an experienced teacher with 15 years' experience in teaching mathematics. He is a Bachelor of Science holder, who specialises in mathematics education. He is currently teaching Grade 5 in a rural school, passionate about teaching and believes that all lessons should be learner-centered. For his lessons, he used curriculum materials supplied by Education District and believes that there was a need to supplement these materials. In his fraction lessons, he used visual representations, and moved from concrete to the semi-concrete and finally to numerical symbols (symbolic representation). Ben's enthusiasm for teaching was evident in his interactions with his learners. His classroom instruction was in such a way that the learners were actively involved from the beginning to the end of the lesson and little time was lost on organising the class or getting the learners to pay attention. During instruction, he moved around the classroom ensuring that each learner in the class participated fully in any given activity. He guided his learners as they worked on the activities and when necessary corrected them as he demonstrated the connections between different representations.

During the lesson observations, it was noticed that Ben drew upon different kinds of representations in his teaching of fraction from readily available resources. This approach was also emphasised in his interview. There were some instances when he drew upon physical representations, using stones as counters for learners to demonstrate sets of objects in his first lesson so that the learners could understand better the part-whole interpretation of fraction. In the first lesson, the learners were actively involved as they worked in groups creating and partitioning sets to form fractions. Here, learners were instructed on how to divide a set of eight into four equal parts. In the course of the instruction, Ben moved around ensuring that each learner was participating in the activity. Then he asked the learners in unison, each set is what of the whole group? 
The learners responded, 'one-fourth'. Ben instructed a learner to write on the board $\frac{1}{4}$ of $8=2$. The activity continued for about $15 \mathrm{~min}$, as learners worked on finding fraction of different sets of stones.

Ben drew upon visual representations in his second lesson by introducing addition of fraction with an activity involving the learners. He used learners to illustrate the part-whole definition of fraction using sets, and also demonstrated the addition of fractions with common denominators using the four-seater desks as a resource. Below is a transcript of teacher Ben's introductory lesson where a four-seater desk was used as a convenient physical representation showing a set of four; the number of people at the two desks were taken as a unit.

T: How many people can be seated on the desk? (Ben, teacher, male)

L: Four on each desk [in unison] (Learners, Grade 5, gender unspecified)

T: Now let us assume that we have two people in one desk and one person in another desk; we are then asked to combine the different people in the two desks. What fraction of the people will the desks occupy? How are we going to do this? (Ben, teacher, male)

L: By joining the two desks [in unison] (Learners, Grade 5, gender unspecified)

Ben distributed two pieces of paper to the learners and asked them to divide each piece of paper into four equal parts, as each piece represented each desk that should occupy four people. He sticked the two pieces on the board and asked the learners to represent the situation:

L: We start by shading (Learners, Grade 5, gender unspecified)

T: Yes, we will shade two parts. (Ben, teacher, male) [A learner stands up to shade using a marker]. Did he shade correctly? Can another learner shade the other part [Another learner stands up to shade one more].

T: We have shaded two fractions; the first is 2 out of 4 and the other is 1 out of 4 . That is $\frac{2}{4}$ and $1 / 4$. What is the denominator of the fraction you will get after addition of $\frac{2}{4}$ and $\frac{1}{4}$ ? (Ben, teacher, male) L: four (Learners, Grade 5, gender unspecified)

$\mathrm{T}$ : four? (Ben, teacher, male)

L: 8 (Learners, Grade 5, gender unspecified)

T: Ok. Let us calculate it; the first desk has space for 4 people and second desk will also contain just four people, so each of the desk will contain just four people so the denominator of the new fraction will still be ' 4 ' because none of the desks will contain more or less than ' 4 people'. Then how many people are seated altogether in the desks? (Ben, teacher, male)

L: Three (Learners, Grade 5, gender unspecified)

T: The addition of $\frac{2}{4}$ and $1 / 4$ will give us what? (Ben, teacher, male)

L: 3/4 [in unison] (Learners, Grade 5, gender unspecified)

T: Very correct. If we say two-eighths plus one-eighth, the answer is what? (Ben, teacher, male)

L: Most of the learners responded three-eighths, that is, $\frac{3}{8}$.
T: Now we have to find out if the answer is correct by calculating $\frac{2}{8}+\frac{1}{8}$ on a square card. Let us use the square on the board to make it easy. Now we want to find the sum of the two fractions. [He pastes the two squares together to form one rectangle, broken down into eight parts to demonstrate the result]. The teacher, first coloured two parts out of the eight parts, then coloured onr part out of the same eight parts, the total coloured parts is 3 out of 8 parts. Then $\frac{2}{8}+\frac{1}{8}=\frac{3}{8}$. (Ben, teacher, male)

Ben then instructed the learners to move into smaller groups. Using a 5-cm long rectangular piece of paper, he asked each learner to use 1 piece of paper divided into 5 pieces to represent and calculate $\frac{1}{5}+\frac{3}{5}$. He moved around the class attending to each group, guiding learners through probing and asking questions.

In terms of the symbolic representation of fraction, Ben continually emphasised correct verbalisations of numerical fraction symbols by stressing that learners should not verbalise the fraction $\frac{2}{4}$ as 'two over four' because according to him, 'over' means something that has gone past. Instead the learners should say 'two-fourth' or two out of four parts. Whenever, he wrote fraction on the board, he often linked the symbolic representation to the correct verbal representation. The emphasis of the words 'fourths' and 'halves' is important to help learners see the 'fourths' as the size of the objects that were being counted, whilst the three was the number of objects being counted.

Ben used both English and isiZulu, but English often and isiZulu was mainly used to clarify certain points when he felt learners did not understand as confirmed during classroom observation. The reason given in the interview was that if the only language of instruction in the classroom is English, some learners who cannot speak English might well be scared to ask questions. The use of the different modes of representation helped improve his learners' understanding of addition of fraction at different rates. Ben used more than one mode of representation because he believed that people have different learning styles and, therefore, using different representations catered for the different learning styles in the classroom.

\section{Teacher 2: Will}

Will has 15 years' experience in teaching mathematics. He holds a BSc that specialises in mathematics education but can also teach life science. He is currently teaching Grade 5 in an urban school. He is passionate about teaching and believes that learners should be taught and guided in learning mathematics having an assumption that the learners attend lessons after school. He used demonstrations in his lessons. All physical and visual aids that he used in the classroom instructions were done as demonstration with learners as observers, although he drew diagrams to illustrate the addition of fraction. The learners participated actively only when they were called upon to write mathematical sentences or symbols on the board. He arrived late for both his lessons that were further delayed because the learners were so rowdy and he had to make them settle down before commencement of lesson. 
Will used different kinds of representations in his teaching of fraction. In terms of physical and visual representations, Will used pens of different colours as counters during the demonstration of fraction. He further demonstrated in his first lesson the definition of fraction using a diagram to explain that the set of five sweets presented a whole and that once a person starts sharing them, fractions are the result. $\mathrm{He}$ emphasised whilst using diagrams that the number of parts into which the whole is divided represents the denominator and the shaded area represents the numerator. He wrote $\frac{2}{8}+\frac{1}{8}=\frac{3}{8}$ in his second lesson and emphasised the rule that when you add two fractions with a common denominator, you add only the numerator. However, he did not draw attention to why the denominator remains the same. The learners spent much of the time laboriously copying down the diagrams from the board.

In terms of making links between the verbal and symbolic representation, Will did not seem to mind how learners verbalised the symbols, paying little attention to correct terminology. Will used only English as a medium of instruction. During interview, Will attributed this to the culture of the school, an English medium school with diverse nationalities. At no point during the observations did he focus on the meaning of a fraction such as $\frac{2}{4}$, which he referred to as 'two over four' instead of two-fourth. The only thing Will cautioned his learners against was using a slanted line (/) to separate numerator from denominator, telling them instead to use the horizontal line (-).

At one point, Will used a real-life problem to explain the part-whole definition of a fraction. The following problem was used by Will:

$\mathrm{Mr}$ Themba has five sweets. He gives three sweets to Shozi and one sweet to Mthethwa. What fraction of the sweets did Mthethwa get? Also what fraction of sweets did Shozi and Mthethwa get altogether? (Will, teacher, male)

He read out the problem aloud and then asked what fraction did Mthethwa get? When nobody answered, he wrote down the answer of $\frac{1}{5}$. Will then posed the second part of the question to his learners. He asked them for the answer, but again nobody answered. He then wrote $\frac{3}{5}+\frac{1}{5}=$ ? on the board. He asked the learners how they would add these fractions. In unison they answered the question saying 'we add the numerators'. His next question was 'what is $3+1$ ' and received the chorus answer of ' 4 '. He then wrote the answer of $\frac{4}{5}$ on the board. He then asked the learners to copy down the question and the answers from the board, which they spent the rest of the lesson doing. Although Will often mentioned in his interview that he preferred to use various representations to teach fractions, he mainly used the area model of shaded parts divided by the total parts to represent fraction.

\section{Teacher 3: Greg}

Greg had 15 years' experience in teaching mathematics. He holds a Bachelor Degree in Education with major in mathematics education. He was teaching Grade 5 in a semiurban school. Greg is a very active teacher and one can tell that he is passionate about teaching mathematics. Greg believes that learners should be actively involved in the learning process. Even though all instructions were whole group discussions, the learners were given opportunities to volunteer to do certain special tasks. He used a fraction chart to give learners a chance to show their understanding by having them demonstrate certain ideas to the rest of the class.

In the first lesson, Greg used apples as manipulative when adding numbers. He also used diagrams, pictures and fraction charts when teaching addition of fractions. He used a fraction chart as follows:

T: Using the fraction chart add $\frac{1}{5}$ and $\frac{3}{5}$ ? (Greg, teacher, male)

L: [unison] $\frac{4}{5}$ (Learners, Grade 5, gender unspecified)

$\mathrm{T}$ : [Randomly pointed out some learners to show the addition using fraction chart] Come and show us how you got the answer. (Greg, teacher, male)

L: A circle divided into five equal parts was placed on the chart board. The learners first removed 1 part out of the 5 equal parts to represent $\frac{1}{5}$ and again removed 3 parts out of the same remaining parts to represent $\frac{3}{5}$, making a total of 4 parts removed out of 5 equal-sized parts. Hence, $\frac{1}{5}+\frac{3}{5}=\frac{4}{5}$.

Greg also used a game to help learners generate and accumulate multiples of numbers. The title of the game was 'There is a fire on the mountain'. Learners formed a circle and ran round, with the teacher leading the song. It went like this:

$\mathrm{T}$ : There is a fire on the mountain. (Greg, teacher, male)

L: Run, run, run. (Learners, Grade 5, gender unspecified)

This was repeated three times and then an accumulation of multiples began.

$\mathrm{T}$ : In threes [said when teaching multiples of three]. (Greg, teacher, male)

L: Learners responded by standing in three.

Those learners who did not form a group of three stood aside. The teacher then instructed each group of three learners to count in threes, and so on, with several different numbers called out by the teacher. This game was intended to help learners to practise their three times table, but it was also useful to help learners improve their multiplicative reasoning by helping them understand that a class of larger group of 54 could also be seen as 18 units each consisting of three units each. This way of looking at the decomposition of numbers is essential for the development of a robust understanding of fractions (Boyce \& Norton 2016; Hackenberg 2010). However, the game was just an add-on and did not seem to be linked to further activities or discussion or written follow-up activities that could have helped the learners consolidate the ideas or extend their skills using other multiples. 
In the second lesson, Greg used more examples to explain addition of fractions as follows:

T: You can also add fractions without using a fraction chart. What do we get when we add $\frac{2}{8}$ and $\frac{1}{8}$ ? (Greg, teacher, male)

L: The majority of the learners were quiet, but some responded $\frac{3}{16}$ after doing some calculations on their papers.

T: Now, we will use the fraction chart to add. We take a strip that is two-eighths and another one that is one-eighth [sticks both strips onto the fraction chart]. We see our Least Common Multiple $[L C M]$ is 8 ; we will look at the fraction with denominator 8 . Then we take the strips and stick them adjacent to each other. Then we compare the answer we get with the first answer [sticks strips on chart]. What is the answer? (Greg, teacher, male)

L: Three out of eight. (Learners, Grade 5, gender unspecified)

Another learner demonstrates, counting the parts not covered by the strip, and gets the answer $\frac{5}{8}$. Greg tried to address the misconception by probing the learner further.

T: How did you get the answer three out of eight? (Greg, teacher, male)

The learner was silent and Greg responded to the class.

$\mathrm{T}$ : Yes, the correct answer is three out of eight. You count the part covered by the strips and where it ends is your answer. The part not covered by the strip is not your answer. (Greg, teacher, male)

From the excerpt it can be seen that Greg tried to help a learner deal with the issue of using a fraction chart. The learner had the misconception of counting the remaining parts and not the covered parts. It is important to note that symbolic representation by demonstration dominated Greg's lesson. Whilst using symbolic representations, he would verbally connect the symbols to other representations. For instance, when finding the lowest common denominator, he would remind learners of the pizza they share in their various homes. Greg used English throughout the classroom instruction and the learners were comfortable with that responding well in English. He used verbal language very well, reminding learners of concepts learned in earlier grades or in previous lessons, connecting them with the current lesson. Another reason given by Greg for use of English was that during problem solving, learners will fail to interpret problems on fractions if they were not accustomed to English.

Research Question 2: Is there any difference in the learners' achievement on tasks based on addition of fraction?

To address the second research question, the researchers used mean, standard deviation and gain scores whilst the null hypotheses were tested at 0.05 alpha levels using ANCOVA, which was considered an appropriate statistical tool. However, post hoc analyses were used to determine the instruction group that was most significant.

Table 1 shows that the mean achievement scores and standard deviation of learners who were taught fraction by three different teachers using different teaching approaches. From the table, it is evident that Ben group had 6.15 and
29.27 in the pre-test and post-test scores, respectively, and standard deviation was 3.24 and 7.46 for pre-test and posttest, respectively. Also, the mean of the learners who were taught fraction by Will was 6.23 and 25.72 in the pre-test and post-test, respectively, with standard deviation of 3.15 and 4.98 , respectively, whilst the mean of the learners who were taught the same fraction by Greg was 6.07 and 18.63 for pre-test and post-test in that order, with standard deviation being 3.60 and 6.76, respectively. However, the mean gain for Ben group was 23.12; Will's group had a mean gain of 10.54, whilst Greg's group had a mean gain of 12.56. This implies that the group taught fraction by teacher Ben had higher achievement level than the learners in other groups. However, there was a need to identify whether the difference was statistically significant with ANCOVA analysis:

$\mathrm{H}_{0}$ : There is no significant difference in the mean performance scores of learners taught fractions by different teachers using different teaching approaches.

Table 2 shows the summary of the one-way ANCOVA table on learners' post-test scores on the achievement of fraction by teachers Ben, Will and Greg. From the data in the table, it is evident that there is a significant difference between the mean achievement scores of learners in the different groups at 0.05 level of significance. This is because the $p$-value is 0.00 . Since the $p$-value of 0.00 is less than 0.05 , we reject the null hypothesis. Hence, there is the need to statistically find out which teaching group actually caused the significant difference in the study using the use of pairwise comparisons test (post hoc test).

Table 3 shows the summary of the post hoc tests using the pairwise comparisons to show exactly where the difference amongst the groups occurs. The groups (I) compares with

TABLE 1: Mean achievement scores and standard deviations of learners' fraction achievement test scores in Ben, Will and Greg groups.

\begin{tabular}{llcccc}
\hline $\begin{array}{l}\text { Teaching } \\
\text { groups }\end{array}$ & Types of test & $\begin{array}{c}\text { No. of } \\
\text { students }\end{array}$ & Mean & SD & Mean gain \\
\hline Ben & Pre-test & 59 & 6.15 & 3.24 & 23.12 \\
& Post-test & 59 & 29.27 & 7.46 & - \\
\multirow{2}{*}{ Will } & Pre-test & 61 & 6.23 & 3.15 & 10.54 \\
& Post-test & 61 & 16.77 & 4.98 & - \\
\multirow{2}{*}{ Greg } & Pre-test & 57 & 6.07 & 3.60 & 12.56 \\
& Post-test & 57 & 18.63 & 6.76 & - \\
\hline Total & - & $\mathbf{1 7 7}$ & - & - & - \\
\hline
\end{tabular}

SD, standard deviation.

TABLE 2: Summary of analysis of variance analysis of fraction achievement test for post-test mean scores of Ben, Will and Greg teaching groups.

\begin{tabular}{lcccccc}
\hline Source & $\begin{array}{c}\text { Type III sum } \\
\text { of squares }\end{array}$ & Df & $\begin{array}{c}\text { Mean } \\
\text { square }\end{array}$ & $\boldsymbol{F}$ & Sig. & Remark \\
\hline Corrected model & 10891.20 & 3 & 3630.40 & 164.75 & 0.00 & S \\
& 6119.90 & 1 & 6119.89 & 277.72 & 0.00 & S \\
Pre-test & 4795.69 & 1 & 4795.69 & 217.63 & 0.00 & S \\
Groups & 5985.77 & 2 & 2992.89 & 135.82 & 0.00 & S \\
Error & 3812.27 & 173 & 22.04 & - & - & - \\
Total & 101874.00 & 177 & - & - & - & - \\
Corrected total & 14703.47 & 176 & - & - & - & - \\
\hline
\end{tabular}

$\mathrm{S}$, significant; Df, degrees of freedom; $F$, the ratio between group variance within group variance; Sig., significant. 
TABLE 3: Results of analysis of variance analysis of pairwise comparison of means (post hoc test).

\begin{tabular}{llclll}
\hline (I) Group & (J) Group & $\begin{array}{c}\text { Mean } \\
\text { difference (I-J) }\end{array}$ & SE & Sig. & Remark \\
\hline Ben & Will & $12.16^{*}$ & 0.86 & 0.00 & $\mathrm{~S}$ \\
& Greg & $10.62^{*}$ & 0.87 & 0.00 & $\mathrm{~S}$ \\
\multirow{2}{*}{ Will } & Ben & $-12.16^{*}$ & 0.86 & 0.00 & $\mathrm{~S}$ \\
& Greg & $-2.08^{*}$ & 0.87 & 0.00 & $\mathrm{~S}$ \\
\multirow{2}{*}{ Greg } & Ben & $-10.62^{*}$ & 0.87 & 0.00 & $\mathrm{~S}$ \\
& Will & $2.08^{*}$ & 0.87 & 0.00 & $\mathrm{~S}$ \\
\hline
\end{tabular}

Note: Adjustment for multiple comparisons: Least significant difference.

$\mathrm{S}$, significant; SE, standard error; Sig., significant.

*, The mean difference is significant at the 0.05 level of significance.

group $(\mathrm{J})$ in each case. From the column labelled the mean difference, the asterisk $(*)$ next to the value listed means that the two groups being compared are significantly different from one another at $p<0.05$. From the table, the mean difference of Ben's and Will's groups was 12.16, the mean difference of Ben's and Greg's groups was 10.62, whilst the mean difference of Greg's and Will's group was 2.08. The other differences were negative. The analysis showed that Ben's group performed better than Will's and Greg's groups, whilst Greg's group performed better than Will's group. Conclusively, the learners taught by teacher Ben performed better than those learners taught the same fraction content by teachers Greg and Will. However, learners taught by teacher Greg performed better than learners taught by teacher Will. The results of these tests were an indication that teacher Ben's teaching approach produced a significant result than the other two teachers.

\section{Discussion}

Based on the findings of our first research question, this study identified different teaching approaches used by three experienced teachers in teaching of addition of fraction to Grade 5 learners. The qualitative research findings revealed that Ben drew upon different types of classroom interactions; he presented explanations, summaries and instructions to the whole class, whilst at other times he allowed his learners to work in small groups. It is important to note that when this happened, he had clear instructions and had the accompanying resources at hand so that the learners were clear about what they needed to do in their group activities. He gave his learners opportunities to practise the addition of fraction using many examples.

All the lesson time in Ben's classroom was used productively for learning because he assigned follow-up activities for his learners. One of the strengths of Ben's lessons was his use of concrete representations. The benefit of starting with concrete manipulatives is that it builds learners' confidence by giving them a way to test and confirm their reasoning (Hunt, Nipper \& Nash 2011). Moreover, Ben spent much time emphasising the links between the verbal and the symbolic representations, helping learners to see concrete examples of the role of the numerator and denominator in the symbolic representation of fraction. This finding was in line with Azuka (2009), Barmby et al. (2014), Naidoo (2011), who revealed that the use of representations can be more effective when concrete and semi-concrete aids are used in teaching and learning of mathematics.

Ben continually emphasised correct verbalisations of numerical fraction symbols by stressing that learners should not verbalise the fraction $\frac{2}{4}$ as 'two over four'; instead, the learners should say 'two-fourths' or two out of four parts. The emphasis of the words 'fourths' and 'halves' is important to help learners see the 'fourths' as the size of the objects that were being counted, whilst the three was the number of objects being counted. This finding confirms the observation of Hackenberg and Lee (2015) that teaching fraction effectively requires using correct language and technical terms. The primary language of communication observed in Bens' lessons was English, although he sometimes used IsiZulu (learners' first language) in his instructions. Ben used mathematical language to create scaffolds for learners' understanding of addition of fractions. This approach is supported by Hill and Charalambous (2012) who found that correct verbal mathematical language is typical of teachers with high mathematical pedagogical knowledge.

Will's teaching was quite disconnected. Although he is an experienced teacher, in this study Will tried to utilise different interpretations of the part-whole model of the fraction (as the number of selected parts compared with the total number of parts, as well as the relationship between a subset of a group of objects and the group itself). He also neglected the connections between the fraction symbol and the subset of sweets compared with the total number of sweets. He moved quickly to deconstruct the real-life problem by symbolising the fraction, without dwelling on how this was achieved. He left the simple task of working out the answer to the whole number addition of ' $2+1$ ' to his learners to work out. Hence, the problem was deconstructed to a whole number addition problem, instead of an application of addition of fraction.

Another disturbing fact was that in Will's classroom much valuable time was lost on unproductive issues, leaving little time to focus on learning of fractions. Although he used a real-life setting based on a part-whole interpretation of a fraction as a relationship between a subset of a group of objects and the group itself, he did not check whether his learners understood this idea of a fraction. He moved quickly to writing down the fractions without drawing attention to the meaning of the numerator and that of the denominator in that setting. The primary language of communication observed in Will's classroom lessons was English.

Greg is equally an experienced teacher like the other two. In this research Greg utilised many representations but spent little time emphasising the connections between them. The use of the 'fire on the mountain' game presented a useful opportunity to build up and connect the key ideas for multiplicative concepts, but Greg did not expand that knowledge. As identified by the author, an important characteristic affecting individuals' ability to learn fraction 
is the development of 'central multiplicative structures' (Lamon 2007:660). The 'fire on the mountain' game could have helped develop learners' multiplicative reasoning through some of the stages identified by Hackenberg (2010). Using the game, a larger group of 54 could also be seen as 18 units each consisting of three units each, which represents 'a unit of units' structure' (Hackenberg \& Lee 2015:206). A crucial extension of this understanding should have been learners' ability to move flexibly between the units of units. However, Greg's use of 'fire on the mountain' game was just an add-on and did not link to follow-up activities that could have helped the learners consolidate the ideas of multiplication concepts.

Greg's main form of classroom engagement was with the whole group. Greg stated during interview that using physical and visual objects was very interesting because the learners were able to relate the visual to the physical one. However, there was not much evidence of him making these connections. He often moved to a different activity abruptly without making the connections explicit. Although teacher demonstration dominated Greg's lessons, the learners also actively participated in demonstrations and were given opportunities to explain their answers. Greg's teaching was dominated by his own explanations and demonstrations, and he did not give his learners any opportunities to work together to find their own answers. However, Greg in his lessons feels that it is necessary to refer to an LCM when adding fractions with the same denominator because of the need to establish the fact that we cannot add fractions with different denominators, until you determine the 'least common denominator'. Greg used English throughout his lessons and the learners were comfortable with that, responding well in English.

The observations revealed that the three teachers' approaches were quite similar in terms of use of representations in teaching addition of fraction. With respect to the kind of representations observed during classroom instruction, emphasis on one representation over another depends on the choice of the teacher. Will and Greg used the different modes of representations identified by Lesh, Post and Behr (1987), whilst Ben's classroom instruction used all the modes except the contextual representation. In Ben's lessons, the learners handled the materials themselves as they were actively engaged in group activities. Will used the manipulatives as a demonstration tool in teacher-led whole class discussions. Greg used physical representations tool during teacher-led whole group discussions, and his learners were actively involved to a smaller extent than Ben's learners were.

Across the three classes, the measurement interpretation of fraction was quite neglected. None of the teachers used the number line as a tool to represent fraction although Greg referred to it fleetingly in his interview. A strong understanding of a fraction as a measure, such as a length on a number line, can form the basis for students' understanding of the magnitude and ordering of fraction
(Boyce \& Norton 2016; Siegler et al. 2011). However, none of the teachers drew upon the number line in their lessons. These findings agree with the observations of Hecht et al. (2003) that measurement interpretation of fraction is often neglected in teaching of fractions. In addition, other researchers (e.g. Boyce \& Norton 2016; Siegler et al. 2011) observed that a strong understanding of a fraction as a measure, such as a length on a number line, is crucial also for learners' future mathematics achievement.

The findings from the second research question based on results from the ANCOVA using the pre-test as the covariate confirm what the classroom observations and interviews suggested. Ben's teaching regarding the addition of fraction was more effective than the other two teachers. The improvement in the scores of the learners from his class was higher than that of the learners from the other two classes. This difference was statistically significant. The improvement for Greg's class was also higher than that of Will's class. And this difference was also statistically significant.

This study has shown how teaching the same mathematics content by three different teachers using varied teaching approaches resulted in different learning gains for their respective learners. It is possible to pinpoint some specific factors that could have led to the improvement in Ben's learners: a combination of good practices and multiple use of representations brought together by Ben in his classroom instruction could explain the better results achieved by his learners. This finding is in line with Green and Hall (1997) and Tripathi et al. (2008) who stressed that making multiple connections amongst mathematical representations provides a unique perspective for understanding mathematical concepts. These connections between and within representations are a necessary strategy to support learners' understanding of fraction (NCTM 2014). Moreover, the use of mother tongue could be one of the reasons for improved performance in Ben's class observed. Van Laren and Goba (2013) observed that learners' performance improved when they were taught mathematics in their home language. On the contrary, Odili (2006) observed learners' poor performance and negative attitude from the society when learners are taught mathematics through their home language.

\section{Conclusion}

This study revealed how three teachers predominantly used different teaching approaches in teaching addition of fraction. It also revealed that learners' success depends on the use, flexibility in terms of moving from one type of representation to another, and teachers' insights and abilities to make connections between representations when teaching fraction. This attribute was displayed by Ben in his classroom observations and could explain for the better performance of his learners in this study. This study has provided empirical support for the intuitive notion that when teachers possess an in-depth understanding of mathematics, their learners learn more (Hill et al. 2005). 
The authors argue that if learners do not develop a sound understanding of the concept of fractions, their subsequent work in simplification of algebraic fractions becomes severely compromised. This position is in line with Ubah and Bansilal's (2018) observations that for many learners their knowledge of simplification of fractions depends on basic understanding of the meaning of fraction. Hence, mathematics teachers should endeavour to facilitate learners' conceptual knowledge of fraction by using appropriate teaching approach in their instruction, namely, learner-centred approach, activity-based learning and use of multiple representations.

One limitation of this study is a very small percentage of flawed test items in FAT, but the questions did not affect learners' responses to the test items because the author made oral correction before commencement of the test. The study recommends that primary school mathematics teachers should adopt a good combination and multiple use of representation in teaching and learning of fraction. The study recommends that pre-service primary mathematics teachers should be provided with more structured opportunities to improve their understanding of different interpretations of fraction. Above all, teacher training institutions should develop mathematics teachers in line with the use of multiple representations, learner-centred approach, activity-based learning and use of mother tongue in teaching fraction.

This research provided empirical evidence that proffers solution to the numerous questions about how teachers could facilitate learners' construction of rational number knowledge and how teachers' experiences and practices could add to such knowledge. It is essential that teacher professional development agencies and school management teams provide structured opportunities for teachers to start sharing their experiences with their colleagues and engaging in joint reflections.

\section{Acknowledgements}

The author would like to thank the three teachers (who wished to be anonymous) for their participation in the study.

\section{Competing interests}

The author declares that she has no financial or personal relationships that may have inappropriately influenced her in writing this research article.

\section{Author's contribution}

I.J.A.U. is the sole author of this research article.

\section{Funding information}

This research received no specific grant from any funding agency in the public, commercial or not-for-profit sectors.

\section{Data availability}

The data that support the findings of this study are available from the author upon reasonable request.

\section{Disclaimer}

The views and opinions expressed in this article are those of the author and do not necessarily reflect the official policy or position of any affiliated agency of the author.

\section{References}

An, S., Kulm, G. \& Wu, Z., 2004, 'The pedagogical content knowledge of middle school, mathematics teachers in China', Journal of Mathematics Teacher Education 7 , 145-172. https://doi.org/10.1023/B:JMTE.0000021943.35739.1c

Azuka, B.F., 2009, Active learning in the mathematics classroom, Lecture note during the workshop for the retraining of primary and JSS teachers on the implementation of new UBE curriculum and continuous assessment in schools, Marvelous Mike Press, Abuja.

Barmby, P., Bolden, D.S., Raine, S. \& Thompson, L., 2014, 'Developing the use of diagrammatic representations in primary mathematics through professional diagrammatic representations in primary mathematics through professional
development', Educational Research 55(3), 263-290. https://doi.org/10.1080/ development', Educational
00131881.2013 .825164

Barton, B., 2008, The language of mathematics: Telling mathematical tales, Springer, New York, NY.

Barwell, R. (ed.), 2009, 'Chapter 5. Mathematical word problems and bilingual learners in England', Multilingualism in mathematics classrooms, pp. 63-77, Blue Ridge Summit, Multilingual Matters, Bristol. https://doi.org/10.21832/ 9781847692061-007

Behr, M., Harel, G., Post, T. \& Lesh, R., 1993, 'Rational numbers: Toward a semantic analysis-emphasis on the operator construct', in T.P. Carpenter, E. Fennema \& T.A. Romberg (eds.), Rational numbers: An integration of research, pp. 13-47, Lawrence Erlbaum, New Jersey, NJ.

Booth, J.L., Newton, K.J. \& Twiss-Garrity, L.K., 2014, 'The impact of fraction magnitude knowledge on algebra performance and learning', Journal of Experimental Child Psychology 9(1), 110-118. https://doi.org/10.1016/j.jecp.2013.09.001

Boyce, S. \& Norton, A., 2016, 'Co-construction of fractions schemes and units coordinating structures', The Journal of Mathematical Behavior 41, 10-25. https://doi.org/10.1016/j.jmathb.2015.11.003

Charalambous, C.Y. \& Pitta-Pantazi, D., 2005, 'Revisiting a theoretical model on fractions: Implications for teaching and research', in H.L. Chick \& J.L. Vincent (eds.), Proceedings of the 29th Conference of the International Group for the Psychology of Mathematics Education, Vol. 2, pp. 233-240, PME, Melbourne.

Chinnappan, M., 2006, 'Role of digital technologies in supporting mathematics teaching and learning: Rethinking the terrain in terms of schemas as epistemological structures', in C. Hoyles, J.B. Lagrange, L.H. Son \& N. Sinclair (eds.), Proceedings of the Seventeenth Study Conference of the International Commission on Mathematical Instruction, pp. 98-104, Hanoi Institute of Technology and Didirem Universite Paris.

Chinnappan, M. \& Forrester, T., 2014, 'Generating procedural and conceptual knowledge of fractions by pre-service teacher's mathematics education research group of Australasia', Mathematics Education Research Journal 26, 871-896. https://doi.org/10.1007/s13394-014-0131-x

Cramer, K. \& Wyberg, T., 2009, 'Efficacy of different concrete models for teaching the part-whole construct for fractions', Math, Think, Learn 11(4), 226-257. https:// doi.org/10.1080/10986060903246479

Cramer, K.A., Post, T.R. \& delMass, R.C., 2002, 'Initial fraction learning by fourth- and fifth-grade students: A comparison of the effects of using commercial curricula with the effects of using the rational number project curriculum', Journal for Research in Mathematics Education 33(2), 111-144. https://doi.org/10.2307/ 749646

Creswell, J.W., 2011, 'Controversies in mixed methods research', in N. Denzin \& Y.S. Lincoln (eds.), The Sage handbook of qualitative research, 4th edn., pp. 269-283, Sage Publications, Thousand Oaks, CA.

Department of Education, 2012, National curriculum statement Grades R-12, National Department of Education, Pretoria.

Duval, R., 2006, 'A cognitive analysis of problems of comprehension in the learning of mathematics', Educational Studies in Mathematics 61, 103-131. https://doi. org/10.1007/s10649-006-0400-z

Eggen, P. \& Kauchak, D., 2004, Educational psychology: Windows on classrooms, Pearson Prentice Hall, Upper Saddle River, NJ.

Essien, A.A., 2018, 'The role of language in the teaching and learning of early grade mathematics: An 11-year account of research in Kenya, Malawi and South Africa', African Journal of Research in Mathematics, Science and Technology Education 22(1), 48-59. https://doi.org/10.1080/18117295.2018.1434453

Flevares, L.M. \& Perry, M., 2001, 'How many do you see? The use of non-spoken representations in first-grade mathematics lessons', Journal of Educationa Psychology 93(2), 330-345. https://doi.org/10.1037/0022-0663.93.2.330

Fuchs, L.S., Schumacher, R.F., Long, J., Namkung, J., Hamlett, C.L., Cirino, P.T. et al., 2013, 'Improving at-risk learners' understanding of fractions', Journal of Educational Psychology 105(3), 683-700. https://doi.org/10.1037/a0032446

Green, J.G. \& Hall, R., 1997, 'Practicing representations: Learning with and about representational forms', Phi Delta Kappan International 78(5), 361-367.

Hackenberg, A.J., 2010, 'Students' reasoning with reversible multiplicative relationship', Cognition and Instruction 28(4), 383-432. https://doi.org/10.1080/07370008.2010. 511565 
Hackenberg, A.J. \& Lee, M.Y., 2015, 'Relationships between students' fractional knowledge and equation writing', Journal for Research in Mathematics Education 46(2), 196-243. https://doi.org/10.5951/jresematheduc.46.2.0196

Harris, A.D., McGregor, J.C., Perencevich, E.N., Zhu, J., Peterson, D.E. \& Finkelstein, J., 2006, 'The use and interpretation of quasi-experimental studies in medical informatics', Journal of the American Informatics Association 13(1), 16-23. https://doi.org/10.1197/jamia.M1749

Hecht, S.A., Close, L. \& Santisi, M., 2003, 'Sources of individual differences in fraction skills', Journal of Experimental Child Psychology 86(4), 277-302. https://doi. org/10.1016/j.jecp.2003.08.003

Hill, C.E., Knox, S., Thompson, B.J., Williams, E.N., Hess, S.A. \& Ladany, N., 2005 'Consensual qualitative research: An update', Journal of Counselling Psychology 52(2), 196-205. https://doi.org/10.1037/0022-0167.52.2.196

Hill, H. \& Charalambous, C.Y., 2012, 'Knowledge, curriculum use and quality of instruction: Unpacking a complex relationship', Journal of Curriculum Studies 44(4), 443-446. https://doi.org/10.1080/00220272.2011.650215

Hsieh, H. \& Shannon, S.E., 2005, 'Three approaches to qualitative content analysis', Qualitative Health Research 15(9), 1277-1288. https://doi.org/10.1177/10497 32305276687

Hunt, A.W., Nipper, K.L. \& Nash, L.E., 2011, 'Virtual vs. concrete manipulatives in mathematics teacher education: Is one type more effective than the other?', Current Issues in Middle Level Education 16(2), 1-6. https://doi.org/10.20429/ gamte.2008.020103

Kieren, T.E., 1976, 'On the mathematical, cognitive, and instructional foundations of rational numbers', in Lesh, R. (ed.), Number and measurement: Papers from a research workshop, pp. 101-144, ERIC/SMEAC, Columbus, OH.

Klob, D.A., 1984, Experiential learning, Prentice Hall, Englewood Cliffs, NJ.

Lamon, S.J., 2007, 'Rational numbers and proportional reasoning: Toward a theoretical framework for research', in F.K. Lester (ed.), Second handbook of research on mathematics teaching and learning, pp. 629-667, Information Age Publishing, Charlotte, NC.

Lesh, R., Behr, M. \& Post, T., 1987, 'Rational number relations and proportions', in C. Janiver (ed.), Problems of representations in the teaching and learning of mathematics, pp. 41-58, Lawrence Erlbaum, London.

Muraka, A., 2008, 'Mathematics teaching and learning as a mediating process: The case of tape diagrams', Journal of Mathematical Thinking and Learning 10(4), 374-406. https://doi.org/10.1080/10986060802291642

Naidoo, J., 2011, 'Exploring master teachers' use of visuals as tools in mathematics classrooms', Doctoral thesis, University of KwaZulu-Natal.

National Council of Teachers of Mathematics (NCTM), 2000, Principles and standards for school mathematics, National Council of Teachers of Mathematics, Reston, VA.

National Council of Teachers of Mathematics (NCTM), 2014, Principles to actions: Ensuring mathematical success for all, National Council of Teachers of Mathematics, Reston, VA.
Nnachi, R.O., 2009, Advanced psychology of learning and scientific enquiries, Totan Publishers, Owerri.

Norton, A. \& Boyce, S., 2013, 'A cognitive core for common state standards', Journal for Mathematical Behavior 32(2), 266-279. https://doi.org/10.1016/j.jmathb. 2013.01 .001

Odili, G.A., 2006, A teaching perspective, Rex Charles and Patrick Limited, Nimo.

Ratcliff, D., 2012, 15 methods of data analysis in qualitative research, viewed 27 June 2017, from https://www.psychsoma.co.za/files/15methods.pdf.

Sauro, J., 2015, 'SUPR-Q: A comprehensive measure of the quality of the website user experience', Journal of Usability Studies 2(10), 68-86.

Setati, M., 2008, 'Access to mathematics versus access to the language of power: The struggle in multilingual classrooms', South Africa Journal of Education 28(1), 103-116.

Setati, M., Chitera, N. \& Essien, A., 2009, 'Research on multilingualism in mathematics education in South Africa: 2000-2007', African Journal of Research in Mathematics 13(1), 65-80. https://doi.org/10.1080/10288457.2009.10740662

Siegler, R.S., Thompson, C.A. \& Schneider, M., 2011, 'An integrated theory of whole number and fractions development', Cognitive Psychology 62(4), 273-296. https://doi.org/10.1016/j.cogpsych.2011.03.001

Stoblein, M., 2009,'Activity-based Learning Experiences in Quantitative Research Methodology for (Time-Constrained) Young Scholars - Course Design and Effectiveness', POMS 20th Annual Conference, Orlando, Florida, U.S.A., May 01-04, 2009, pp. 1-33.

Tripathi, S., Mehrotra, G.K. \& Dutta, P.K., 2008, 'Chitosan based antimicrobial films for food packaging applications', E-Polymers 8(1), 1-7. https://doi.org/10.1515/ epoly.2008.8.1.1082

Ubah, I.J.A. \& Bansilal, S., 2018, 'Pre-service primary mathematics teachers' understanding of fractions: An action-process-object-schema perspective', South African Journal of Childhood Education 8(2), a539. https://doi.org/10.4102/sajce. v8i2.539

Van Laren, L. \& Goba, B., 2013, 'They say we are crèche teachers': Experiences of reservice teachers taught through the medium of isizulu', Pythagoras 31(1), 21-28. https://doi.org/10.4102/pythagoras.v34i1.216

Vanderburg, R.M., 2006, 'Reviewing research on teaching writing based on Vygotsky's theories: What can we learn?', Reading and Writing Quarterly 22(4), 375-393. theories: What can we learn?', Reading and
https://doi.org/10.1080/10573560500455778

Vygosky, L.S., 1978, Mind in society, Harvard University Press, Cambridge, MA.

$\mathrm{Wu}, \mathrm{H} ., 2014$, Fractions, decimals and rational numbers, viewed n.d., from https:// citeseerx.ist.psu.edu/viewdoc/download?doi=10.1.1.648.1138\&rep=rep1\&type= pdf.

Zaretskii, V.K., 2009, 'The zone of proximal development', Journal of Russian and East European Psychology 47(6), 70-93. https://doi.org/10.2753/RPO10610405470604 


\section{Appendix 1}

\section{Fraction achievement test (FAT)}

Instructions: Simplify the following fractions on the spaces provided and encircle the correct option.

1. $1 / 4+1 / 4=$
(A) $1 / 4$
(B) $1 / 2$
(C) $1 / 3$

2. $\frac{2}{10}+\frac{7}{10}=$
(A) $14 / 100$
(B) $9 / 100$
(C) $9 / 10$

3. $\frac{1}{3}+\frac{1}{3}=$
(A) $2 / 3$
(B) $1 / 3$
(C) 1

4. $\frac{4}{9}+\frac{5}{9}=$
(A) 1
(B) $9 / 18$
(C) 0

5. $\frac{1}{5}+\frac{1}{5}=$
(A) $1 / 5$
(B) $2 / 5$
(C) $2 / 10$

6. $\frac{1}{8}+\frac{1}{8}=$
(A) $1 / 4$
(B) $1 / 8$
(C) $1 / 64$

7. $\frac{2}{5}+\frac{2}{5}=$
(A) $4 / 10$
$\begin{array}{ll}\text { (B) } 4 / 5 & \text { (C) } 4 / 25\end{array}$

8. $\frac{2}{5}+\frac{1}{5}=$
(A) $3 / 10$
(B) $3 / 25$
(C) $3 / 5$

9. $\frac{3}{10}+\frac{4}{10}=$
(A) $7 / 10$
(B) $7 / 20$
(C) $12 / 20$

10. $\frac{1}{12}+\frac{5}{12}+\frac{3}{12}=$
(A) $3 / 4$
(B) $15 / 12$
(C) $5 / 12$

11. $\frac{2}{7}+\frac{3}{7}=$
(A) $6 / 7$
$\begin{array}{ll}\text { (B) } 6 / 49 & \text { (C) } 5 / 7\end{array}$

12. $\frac{3}{8}+\frac{5}{8}=$
(A) $15 / 64$
$\begin{array}{ll}\text { (B) } 8 / 16 & \text { (C) } 1\end{array}$

13. $\frac{1}{7}+\frac{3}{7}+\frac{1}{7}+\frac{1}{7}=$
(A) $6 / 49$
(B) $6 / 7$
(C) $6 / 14$

14. $\frac{4}{6}+\frac{1}{6}=$
(A) $5 / 36$
$\begin{array}{ll}\text { (B) } 4 / 6 & \text { (C) } 5 / 6\end{array}$

15. $\frac{1}{8}+\frac{2}{8}=$
(A) $3 / 8$
$\begin{array}{ll}\text { (B) } 3 / 64 & \text { (C) } 2 / 64\end{array}$ 
16. $\frac{1}{9}+\frac{1}{9}=$
(A) $2 / 9$
(B) $2 / 81$
(C) $1 / 9$

17. $\frac{6}{11}+\frac{1}{11}+\frac{3}{11}=$
(A) $10 / 11$
(B) $6 / 121$
(C) $18 / 121$

18. $\frac{1}{15}+\frac{3}{15}=$
(A) $4 / 30$
(B) $4 / 15$
(C) $3 / 15$

19. $\frac{3}{8}+\frac{1}{8}+\frac{1}{8}=$
(A) $3 / 8$
(B) $3 / 64$
(C) $5 / 8$

20. $\frac{4}{9}+\frac{1}{9}+\frac{2}{9}+\frac{1}{9}=$
(A) $6 / 9$
(B) $6 / 81$
(C) $8 / 9$

21. $\frac{1}{18}+\frac{2}{18}=$
(A) $1 / 9$
(B) $1 / 6$
(C) $1 / 8$

22. $\frac{3}{4}+\frac{2}{4}=$
(A) $3 / 4$
(B) $1 \frac{1}{4}$
(C) $2 / 4$

23. $\frac{1}{3}+\frac{1}{3}+\frac{1}{3}=$
(A) 1
(B) 0
(C) $1 / 3$

24. $1 / 2+1 / 2=$
(A) $2 / 4$
(B) $1 / 4$
(C) 1

25. Jean needs $2 \frac{1}{4}$ cups of flour to make sugar cookies and $3 \frac{1}{4}$ cups of flour to make peanut butter cookies. What is the total number of cups of flour that Jean will need to make both kinds of cookies?
A. $5 \frac{1}{3}$
(B) $5 \frac{1}{2}$
(C) $5 \frac{1 / 4}{4}$

26. Khoza ate $3 / 15$ of the pizza for lunch whilst Makhudu ate $1 / 15$ of the same pizza. What is the total fraction of pizza that they ate for lunch?
(A) $3 / 15$
(B) $2 / 15$
(C) $4 / 15$

27. A group of 5 campers used a total of 12 gallons of water on a camping trip. Each camper used the same amount of water. How many gallons of water did each camper use?
(A) $1 / 12$
(B) $5 / 12$
(C) $12 / 5$

28. Mr. Morris built a fence to enclose his yard. He put up 2/6 of the fence on Monday. On Tuesday, he put up $1 / 6$ of the fence, and on Wednesday, he put up $1 / 6$ of the fence. What portion of the fence did he put up altogether?
(A) $2 / 3$
(B) $1 / 3$
(C) 6

29. It takes Julia $1 / 4 \mathrm{~h}$ to wash, comb her hair and put on her clothes, and $1 / 4 \mathrm{~h}$ to have her breakfast. How much time does it take Julia to be ready for school?
(A) $1 / 4 \mathrm{~h}$
(B) $1 / 2 \mathrm{~h}$
(C) $1 / 8 \mathrm{~h}$

30. $\frac{6}{13}+\frac{8}{13}=$
(A) $2 / 13$
(B) $7 / 13$
(C) $1 \frac{1}{13}$

31. How many one-fourths would be needed to make a whole?
(A) 2
$\begin{array}{ll}\text { (B) } 3 & \text { (C) }\end{array}$ 
32. In preparation for a dinner, Allen went to the grocery store and got vegetables to make a salad. He picked out $1 / 4$ of a bag of spinach, $1 / 4$ of a bag of romaine and $1 / 4$ of a bag of tomatoes. How many bags of vegetables did Allen get in total? (Assume that the bags were of the same size.)
(A) $1 / 4$
(B) $3 / 12$
(C) $3 / 4$

33. Jeanette visited a toy shop with her younger brother. Near the register, there were jars filled with tiny items. They saw $1 / 9$ of a jar of toy soldiers, $1 / 9$ of a jar of rings and 2/9 of a jar of key chains. Altogether, how many jars would these items fill? (Assume that the jars were of the same size.)
(A) $4 / 27$
(B) $2 / 9$
(C) $4 / 9$

34. Mimi's science class recorded the rainfall each day. They recorded $1 / 7$ of a centimetre of rain on Monday, $2 / 7$ of a centimetre of rain on Tuesday and 2/7 of a centimetre of rain on Wednesday. How many centimetres of rain did the class record in all? (Assume that the quantity of rain was same for each day.)
(A) $5 / 17$
(B) $3 / 7$
(C) $5 / 27$

35. A group of students baked pies and sampled the results. Afterwards, the instructor noted what remained. He saw $1 / 11$ of a pie filled with apples, $3 / 11$ of a pie filled with pears and $5 / 11$ of a pie filled with cherries. If he combined the leftover, what fraction of the whole pie can he make? (Assume that the pies were of identical size.)
(A) $9 / 33$
(B) $9 / 22$
(C) $9 / 11$

36. Desmond's family ordered pizza to eat during an American football game. Desmond ate $3 / 8$ of a pizza. His mother ate $1 / 8$ of a pizza, and his father ate $3 / 8$ of a pizzas. If all the pizzas were of the same size, how many pizzas did Desmond's family eat in all?
(A) $7 / 8$
(B) $3 / 8$
(C) $3 / 24$

37. In preparation for a hike, Layla mixed together some nuts. She used $1 / 10$ of a cup of peanuts, $3 / 10$ of a cup of walnuts and $3 / 10$ of a cup of almonds. What fraction of a cup of ingredients did Layla use in all?
(A) $3 / 30$
(B) $1 / 10$
(C) $7 / 10$

38. Whilst waiting for her family to finish shopping, Linda wandered around the mall. She spent $1 / 5$ of an hour in a game store, $1 / 5$ of an hour in clothing store and $2 / 5$ of an hour in a shoe store. In all, what fraction of an hour did Linda spend wandering around the mall?
(A) $4 / 15$
(B) $2 / 15$
(C) $4 / 5$

39. After the lunch rush, the manager of a bakery checked how much quiche remained. He found $7 / 12$ of a quiche with bacon, $1 / 12$ of a quiche with mushrooms and $1 / 12$ of a quiche with asparagus. Assuming the quiches were all identical in size, how many leftover quiches do we have?
(A) $7 / 12$
(B) $2 / 3$
(C) $3 / 4$

40. Add $1 / 6,2 / 6$ and $1 / 6$
(A) $2 / 9$
(B) $2 / 3$
(C) $1 / 6$ 